\title{
Detection of Phytophthora infestans by Loop-Mediated Isothermal Amplification, Real-Time LAMP, and Droplet Digital PCR
}

\author{
Jean B. Ristaino, ${ }^{1,2, \dagger}$ Amanda C. Saville, ${ }^{1}$ Rajesh Paul, ${ }^{3}$ Donald C. Cooper, ${ }^{4}$ and Qingshan Wei ${ }^{2,3}$ \\ ${ }^{1}$ Department of Entomology and Plant Pathology, North Carolina State University, Raleigh, NC 27695 \\ ${ }^{2}$ Emerging Plant Disease and Global Food Security Cluster, North Carolina State University, Raleigh, NC 27695 \\ ${ }^{3}$ Department of Chemical and Biomolecular Engineering, North Carolina State University, Raleigh, NC 27695 \\ ${ }^{4}$ Mobile Assay, Inc., Boulder, CO 80301
}

\begin{abstract}
Phytophthora infestans is the causal agent of potato late blight, a devastating disease of tomato and potato and a threat to global food security. Early detection and intervention is essential for effective management of the pathogen. We developed a loop-mediated isothermal amplification (LAMP) assay for P. infestans and compared this assay to conventional PCR, real-time LAMP, and droplet digital PCR for detection of $P$. infestans. The LAMP assay was specific for $P$. infestans on potato and tomato and did not amplify other potato- or tomato-infecting Phytophthora species or other fungal and bacterial pathogens that infect potato and tomato. The detection threshold for SYBR Green LAMP

We adapted the LAMP assay using SYBR Green and a mobile reader (mReader) for use in the field. Detection limits were $584 \mathrm{fg} / \mu \mathrm{l}$ for SYBR Green LAMP read on the mReader, which was more sensitive than visualization with the human eye. The mobile platform records geospatial coordinates and data from positive pathogen detections can be directly uploaded to a cloud database. Data can then be integrated into disease surveillance networks. This system will be useful for real-time detection of $P$. infestans and will improve the timeliness of reports into surveillance systems such as USABlight or EuroBlight.
\end{abstract} and real-time LAMP read with hydroxynaphthol blue and EvaGreen was $1 \mathrm{pg} / \mu \mathrm{l}$. In contrast, detection by conventional PCR was $10 \mathrm{pg} / \mu \mathrm{l}$. Droplet digital PCR had the lowest detection threshold $(100 \mathrm{fg} / \mu \mathrm{l})$.
Keywords: oomycetes, pathogen detection, Phytophthora infestans, vegetables
Phytophthora infestans (Mont.) de Bary is the causal agent of potato late blight, a devastating disease of tomato and potato crops and a threat to global food security. Historically, it caused the Irish potato famine of the $1840 \mathrm{~s}$, and today, late blight continues to threaten global potato and tomato production. The pathogen spreads rapidly from infected plants and if left untreated, crop fields can be destroyed in a matter of days (Bourke 1964; Fry 2008). Late blight is considered a remerging disease owing to the speed of spread and the extent of damage the pathogen can cause (Anderson et al. 2004; Fry et al. 2015). Disease surveillance and forecasting systems are important to monitor pathogen outbreaks and manage disease (Fry et al. 2015; Hu et al. 2012). The development of disease surveillance systems such as USABlight (https://usablight.org) and EuroBlight (http://euroblight.net/) (Cooke et al. 2011; Ristaino et al. 2019) has provided a means for stakeholders to report outbreaks and receive alerts when the pathogen is detected in their area, allowing advanced warning of disease in a given region. Currently in USABlight, all reports are validated by a team of trained scientists. Once a report is made, samples are then sent to a laboratory for further genotyping and phenotyping. There may be delays in reporting owing to expert

${ }^{\dagger}$ Corresponding author: J. B. Ristaino; jean_ristaino@ncsu.edu

Funding: This work was supported in part by U.S. Department of Agriculture Foreign Agricultural Service grant SCRP 5900, a North Carolina State University CALS Deans Enrichment Program grant, the North Carolina State University Chancellor's Faculty Excellence Program (Emerging Plant Disease and Global Food Security Cluster), and the North Carolina State University Kenan Institute for Engineering, Technology and Science.

*The $\boldsymbol{e}$-Xtra logo stands for "electronic extra" and indicates that one supplementary figure and two supplementary tables are published online.

The author(s) declare no conflict of interest.

Accepted for publication 11 October 2019.

(C) 2020 The American Phytopathological Society verification before an outbreak report is mapped. In addition, sample submission via mailing infected leaves or FTA cards (paper-based sample submission cards) and further genotyping can take days to complete. Early detection and identification in fields would enable growers as decision makers to apply fungicide treatments more precisely for control of the pathogen.

PCR has long been a gold standard for species identification of plant microbes when paired with species-specific primers. However, the requirement of thermal cycling for the Taq polymerase to function has limited the usefulness of PCR outside of laboratory settings and delays determination of pathogen identification. The development of isothermal amplification technologies, such as loop-mediated isothermal amplification (LAMP), which use an isothermal polymerase to amplify DNA at a single temperature, is a significant step forward (Notomi et al. 2000). Field-ready LAMP assays that require only a heat block or water bath at the target temperature can be used to successfully amplify DNA.

Bst polymerase is used in LAMP assays and a full reaction can be run in less than an hour at $65^{\circ} \mathrm{C}$ (Notomi et al. 2000). LAMP assays have been developed extensively for detection of a number of different kinds of plant pathogens including 'Candidatus Liberibacter solanacearum' (Ravindran et al. 2012), Sclerotinia sclerotiorum (Duan et al. 2014), Pythium aphanidermatum (Fukuta et al. 2013), Erysiphe necator (Thiessen et al. 2016), and Xanthomonas fragariae (Gétaz et al. 2017).

LAMP assays have also been developed for Phytophthora species. An on-site rapid in-field detection system was developed for $P$. ramorum using LAMP in conjunction with visualization on a lateral flow device (LFD) (Tomlinson et al. 2007, 2010). Other LAMP detection assays have been developed for $P$. melonis and $P$. nicotianae (Chen et al. 2013; Li et al. 2015). Some of these assays use fluorescent intercalating dyes such as SYBR Green for visualization of amplicons (Chen et al. 2013; Li et al. 2015). Metal-ion indicators, such as hydroxynaphthol blue (HNB), have also been utilized as visual dyes and have been incorporated into detection assays for $P$. sojae (Dai et al. 2012) and $P$. infestans (Hansen et al. 2016). Since $\mathrm{HNB}$ reacts to changes in the concentration of $\mathrm{Mg}^{2+}$ ions instead of direct interaction with DNA, it can be added as a component of 
the master mix, reducing the risk of contamination of samples from postreaction opening of tubes (Goto et al. 2009).

LAMP primers have been developed for $P$. infestans using either the internal transcribed spacer (ITS) region or Yptl (Ras-related protein) gene, respectively (Hansen et al. 2016; Khan et al. 2017; Si Ammour et al. 2017). However, none of the previously published LAMP assays integrated the LAMP assay into a field-ready mobile detection platform or uploaded data to a reporting system. In addition, comparisons of conventional LAMP assays to a real-time LAMP, conventional PCR, and the highly sensitive droplet digital PCR (ddPCR) assay have not been done previously to compare threshold levels of detection and sensitivity by the various detection methods.

The primary objectives of our work were as follows: (i) to develop and optimize a LAMP assay specific for the detection of $P$. infestans; (ii) to compare the LAMP assay to conventional PCR, real-time LAMP, and ddPCR; and (iii) to connect the LAMP assay to a mobile platform for reading results and uploading data to a cloud database for reporting and tracking disease.

\section{Materials and Methods}

Isolate sampling and DNA extraction. Twenty-three isolates of $P$. infestans were used to develop the LAMP assay. The isolates included representatives from U.S. lineages (US-1, US-6, US-7, US-8, US-11, US-22, US-23, and US-24) as well as a European and East African (2_A1, previously known as KE-1) lineage. Other Phytophthora species known to infect potato and tomato, as well as isolates of common bacterial and fungal pathogens of potato and tomato, were included to test the specificity of the LAMP assay for $P$. infestans. All isolates were obtained from cultures originally derived from infected host tissue and the sources of isolates are documented (Supplementary Table S1).

DNA was extracted using either a hexadecyltrimethylammonium bromide (CTAB) method (May and Ristaino 2004) or a quick sodium hydroxide extraction method (Wang et al. 1993). For CTAB extraction, fresh mycelia were placed in sterile 1.5$\mathrm{ml}$ microcentrifuge tubes to which $150 \mu$ l of extraction buffer (0.35 $\mathrm{M}$ of sorbitol, $0.1 \mathrm{M}$ of Tris, $0.005 \mathrm{M}$ of EDTA, $\mathrm{pH}$ 7.5, and $0.02 \mathrm{M}$ of sodium bisulfite) was added and each sample was macerated using a Konte pestle. Then $150 \mu \mathrm{l}$ of nuclei lysis buffer (0.2 M of Tris, 0.05 M of EDTA, pH 7.5, 2.0 M of NaCl, $2 \% \mathrm{CTAB}$ ), and $60 \mu \mathrm{l}$ of $5 \%$ sarkosyl [ $N$-laurylsarcosine]) was added and tubes were vortexed and incubated at $65^{\circ} \mathrm{C}$ for 15 to $30 \mathrm{~min}$ in a water bath. After incubation, one volume $(300 \mu \mathrm{l})$ of chloroform/isoamyl alcohol (24:1) was added to each tube and tubes were centrifuged for $15 \mathrm{~min}$ at $13,000 \times \mathrm{g}$ at room temperature. The aqueous phase was removed to a new tube and chloroform extraction was repeated. DNA was precipitated overnight at $-20^{\circ} \mathrm{C}$ in 0.1 volume of $3 \mathrm{M}$ of sodium acetate $(\mathrm{pH} 8.0)$ and two volumes of cold $100 \%$ ethanol. The supernatant was discarded; pellets were washed with $70 \%$ ethanol and dried at room temperature. DNA was suspended in Tris-EDTA (TE; $10 \mathrm{mM}$ of Tris$\mathrm{HCl}$ and $0.1 \mathrm{mM}$ of EDTA, $\mathrm{pH}$ 8.0). For the quick sodium hydroxide extraction method, mycelium was ground with a Konte pestel in 1.5 -ml tubes containing $90 \mu \mathrm{l}$ of $0.5 \mathrm{~N}$ sodium hydroxide and then $3 \mu \mathrm{l}$ of the supernatant was immediately transferred to $300 \mu \mathrm{l}$ of $100 \mathrm{mM}$ Tris, $\mathrm{pH} 8.0$ (Wang et al. 1993). In both cases, DNA was diluted 1:10 (100 to $200 \mathrm{ng} / \mu \mathrm{l})$ for further use.

LAMP primer development. Three sets of primers were developed for the LAMP assay consisting of a standard forward and reverse primer (F3/B3) and FIP/BIP primers and two Loop primers to accelerate the reaction (LoopF/LoopB). FIP and BIP primers are composed of two separate segments of the target region: F1/B1 and F2/B2. The complement of F1 (F1c) is concatenated with F2 to form the FIP primer, whereas the complement of B1 (B1c) is concatenated with B2 to form the BIP primer. The primer locations and target sequences on the ITS DNA sequence are shown in Supplementary Figure S1. PrimerExplorer version 4 (Eiken Chemical Co., Tokyo, Japan; http://primerexplorer.jp/e/) was used to develop primers for LAMP.
The ITS region was selected for the development of LAMP primers based on our previous work with $P$. infestans (Trout et al. 1997). The ITS sequences for 12 Phytophthora species known to infect potato and tomato were compiled from our Lucid Key dataset (Ristaino 2012) and aligned using ClustalW within the alignment program BioEdit (Hall 1999; Thompson et al. 1994) to locate sequence differences unique to $P$. infestans. These sequences were used in PrimerExplorer to develop the primer sets. The top 50 primers with the most mutations were inspected to look for mutations in locations that would significantly increase specificity, such as near the $5^{\prime}$ or $3^{\prime}$ end of the FIP or BIP primer. One primer set was chosen for testing based on location of mutations, GC content, and melting temperature $\left(\mathrm{T}_{\mathrm{m}}\right)$. To increase specificity to $P$. infestans, the FIP and BIP primers were purified using high-performance liquid chromatography (HPLC) (Ravindran et al. 2012) and were designated as FIP_ HPLC and BIP_HPLC (Supplementary Table S2). The set of six primers was used in the LAMP assay with Bst polymerase and produced a set of ladder-like DNA fragments typical of LAMP that can be visualized on an agarose gel (Fig. 1A).

LAMP reaction and visualization with SYBR Green, HNB, or LFD. The LAMP reaction consisted of the following: $2.5 \mu \mathrm{l}$ of $10 \times$ isothermal amplification buffer (New England Biolabs, Ipswich, MA); $3 \mu \mathrm{l}$ of $50 \mathrm{mM} \mathrm{MgSO}_{4} ; 3.5 \mu \mathrm{l}$ of $10 \mathrm{mM}$ dNTPs; $4.5 \mu \mathrm{l}$ of $5 \mathrm{M}$ betaine; $1 \mu \mathrm{l}$ of Bst $2.0 \mathrm{WarmStart}$ DNA polymerase at $8 \mathrm{U} / \mu \mathrm{l}$ (New England Biolabs); $0.5 \mu \mathrm{l}$ of $10 \mu \mathrm{M}$ primers F3, B3, FIP-HPLC, and BIP-HPLC; $0.25 \mu \mathrm{l}$ of $100 \mu \mathrm{M}$ LoopF and LoopB primers; and $7 \mu \mathrm{l}$ of molecular biology grade water (Supplementary Table S2) (Tomlinson et al. 2010). Reactions were run in $25-\mu l$ volumes and included $1 \mu \mathrm{l}$ ( 1 to $10 \mathrm{ng} / \mu \mathrm{l})$ of DNA template. Reactions were run at $65^{\circ} \mathrm{C}$ for $30 \mathrm{~min}$, followed by an increase in temperature to $80^{\circ} \mathrm{C}$ for 5 min to deactivate the Bst polymerase. To reduce the risk of false amplification, separate sets of dedicated pipettes were used for LAMP reagents and master mixes were set up in a sterile laminar flow hood. Assays were run in eight-sample batches (six samples, a positive control, and a negative control).

LAMP results were visualized either through traditional gel electrophoresis or by direct visualization using SYBR Green (Invitrogen,

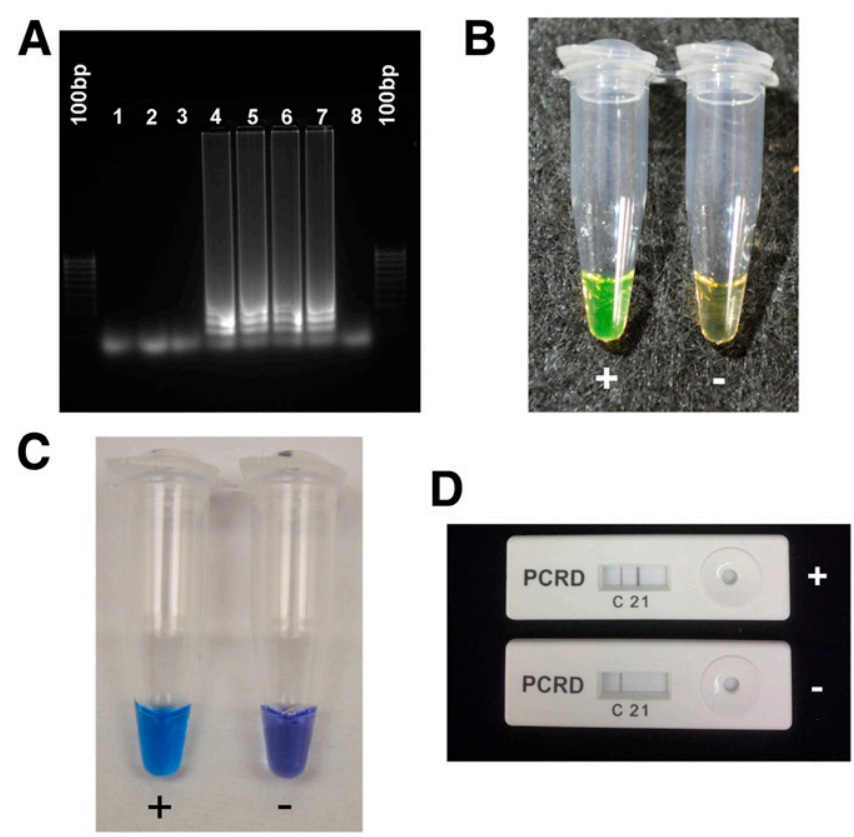

Fig. 1. Loop-mediated isothermal amplification reactions for Phytophthora infestans visualized with A, $1 \%$ agarose gel, B, SYBR Green, and C, hydroxynaphthol blue. D, Lateral flow device showing infected (two bands) and healthy (one band) tissue. A, Lanes 1 to 3 , healthy tubers; lanes 4 to 6 , infected tubers; and lanes 7 to 8 , positive and negative controls, respectively. The first and last lanes are 100-bp ladders. B, SYBR Green for $P$. infestans-infected $(+)$ and healthy $(-)$ leaves. C, Hydroxynaphthol blue for $P$. infestans-infected $(+)$ and healthy $(-)$ leaves. D, Lateral flow device indicating infected (+) band and healthy (-) tissue, no second band. 
Carlsbad, CA). For direct visualization, 1 to $2 \mu l$ of $1,000 \times$ SYBR Green was added directly to the sample post-LAMP and observed for a color change from orange to green to indicate a positive reaction. In other experiments, LAMP assays were also run by adding hydroxynaphthol blue $(1.2 \mu \mathrm{l}$ of $2.5 \mathrm{mM} \mathrm{HNB}$; Millipore Sigma, St. Louis, MO) directly into the LAMP reaction mix either using our protocol or previously published protocols (Hansen et al. 2016). A color change from violet to blue indicates a positive reaction.

The LAMP reaction was also visualized with an LFD (PCRD Nucleic Acid Detectors; Abingdon Health, York, UK). The LoopF primer was labeled with digoxigenin (DIG) (the primer may also be labeled with 6-FAM phosphoamidite according to the manufacturer's instructions), and LoopB was labeled with biotin. After the LAMP reaction was run with the labeled primers (no addition of SYBR Green or HNB), $5 \mu$ l of amplification product was mixed with $70 \mu l$ of PCRD extraction buffer and applied onto PCRD Nucleic Acid Detectors. The LFD was observed for a reaction after $10 \mathrm{~min}$ of incubation at room temperature. The LFD assay was tested using four different lineages of $P$. infestans (US-1, US-6, US-11, and US23 ), as well as a negative control. The experiment was repeated twice.

LAMP specificity. The LAMP primers were tested against 26 isolates of 17 species of bacteria and fungi known to be pathogenic on potato and/or tomato. In addition, the LAMP primers were also tested against isolates of other Phytophthora species known to infect potato and tomato (Mideros et al. 2018; Trout et al. 1997; Yang et al. 2017). DNA extractions from other oomycete and fungal species were first tested for the presence of target pathogen DNA using conventional PCR and primers ITS4 and ITS5 and REP2-I and REP1R-I for bacterial species (Cruz et al. 1996; White et al. 1990). LAMP reactions were visualized using SYBR Green and each isolate was tested at least twice.

LAMP sensitivity. DNA from $P$. infestans isolate 98-64 (US-8) was diluted to $10 \mathrm{ng} / \mu \mathrm{l}$ using a NanoDrop device, and a serial dilution was subsequently generated ranging from $10 \mathrm{ng} / \mu \mathrm{l}$ to $100 \mathrm{fg} / \mu \mathrm{l}$. The dilution series was prepared using sterile molecular-grade water. The LAMP was run using the diluted DNA template and the experiment was repeated three times. Results were evaluated by adding SYBR Green to the samples and examining the resulting color change (Fig. 1). The lowest level of detection was determined as the lowest DNA concentration at which the LAMP reaction produced a positive result across all trials.

Detection in infected potato and tomato tissue. To evaluate the probability of detection of $P$. infestans in infected tubers, an experiment was set up with artificially inoculated potato tubers. Twenty-two organically grown Yukon gold potato tubers were surface sterilized with ethanol and a core approximately $6 \mathrm{~mm}$ in diameter and $2 \mathrm{~cm}$ in length was extracted from each tuber using a sterile cork borer. A 5-mm plug of rye-V8 agar containing actively growing mycelia of $P$. infestans was placed face down inside the tuber and the core was replaced. For the negative controls, the potato core was replaced but not inoculated. Tubers were incubated in the dark at $18^{\circ} \mathrm{C}$ for 1 week. A sample approximately $6 \mathrm{~mm}$ in diameter and $2 \mathrm{~cm}$ in length was taken approximately $2.5 \mathrm{~cm}$ away from the inoculation site and tissue was frozen. DNA was extracted from a 5-mm piece of tuber using a modification of the quick sodium hydroxide extraction method (Saville et al. 2016; Wang et al. 1993). To reduce the amount of gelatinization that occurs between alkaline solutions and starch, the potato tissue was first crushed in $100 \mu$ l of TE buffer (10 mM of Tris and $0.1 \mathrm{mM}$ of EDTA) with a sterile Konte pestle. Then, $50 \mu l$ of this solution was used for the sodium hydroxide extraction. The presence/absence of $P$. infestans DNA in all samples was first verified using conventional PCR with the PINF2/ITS5 primers (Saville et al. 2016). Samples were then tested for detection using SYBR Green LAMP, real-time LAMP, and ddPCR with the methods described below.

The LAMP assay was also used to detect $P$. infestans in fresh and dried infected tomato tissue as well as in dried samples pressed onto FTA cards. FTA cards are commonly used to collect $P$. infestansinfected tissue and DNA embedded on the cards will remain stable at room temperature for years if left dry. Fresh tomato leaves (cultivar Mountain Fresh Plus) were harvested and inoculated with an actively growing isolate of $P$. infestans by spraying the abaxial side of the leaf with distilled water and pressing a sporulating leaf lesion against the abaxial side of the leaf. The freshly inoculated leaf was incubated in a Petri dish containing $1.5 \%$ water agar at room temperature until symptoms were observed. Samples of the infected leaves were removed from the edge of the observed lesion and DNA was extracted using the sodium hydroxide extraction protocol. DNA from a healthy leaf was extracted in a similar manner. Healthy and diseased leaves were also pressed onto FTA cards and additional field collected samples on FTA cards were also tested. DNA was extracted from the FTA cards following the manufacturer guidelines and from dried healthy and field-infected leaves using $\mathrm{NaOH}$ extraction (Wang et al. 1993). All samples were tested using PCR using PINF2/ITS5 primers and the SYBR Green LAMP assay.

Real-time LAMP. False-positive amplification in negative controls can occur in LAMP assays as a result of primer dimerization or the nonspecific binding of primers to nontarget DNA. To investigate methods for minimization of false-positive reactions, we evaluated the performance of the LAMP assay using HNB in parallel with the intercalating dyes EvaGreen in a "one-pot" fluorescent LAMP reaction (Fig. 2) (Kong et al. 2017; Lee et al. 2016).

LAMP primers for the optimization of the reaction using HNB were purchased from Thermo Fisher Scientific. EvaGreen $(20,000 \times)$ was purchased from Biotium. A fresh dilution of EvaGreen dye (20x in deionized water) was prepared each time before making the LAMP master mix. All other reagents were purchased from New England Biolabs. The master mix for the real-time assay consisted of $1 \times$ isothermal buffer, $8 \mathrm{mM}$ of magnesium sulfate, $1.4 \mathrm{mM}$ of dNTPs, $0.8 \mathrm{mM}$ of betaine, $0.32 \mathrm{U} / \mu \mathrm{l}$ of WarmStart Bst polymerase, $120 \mu \mathrm{M}$ of HNB (Sigma-Aldrich), $1 \times$ EvaGreen, $200 \mathrm{nM}$ of F3 and B3, $2 \mu \mathrm{M}$ of FIP and BIP, and $0.8 \mu \mathrm{M}$ of Loop $\mathrm{F}$ and LoopB. The real-time LAMP assay was carried out in $25-\mu 1$ volumes on the CFX Connect Real-Time System (Bio-Rad). The reaction temperature was set to $65^{\circ} \mathrm{C}$, followed by a melt curve analysis. For the melt curve analysis, the temperature of a set of samples of different concentrations of DNA was raised incrementally from 65 to $95^{\circ} \mathrm{C}$. For each $0.5^{\circ} \mathrm{C}$ temperature increment, the samples were kept for $5 \mathrm{~s}$ before measuring the fluorescence. The temperature was then set to $85^{\circ} \mathrm{C}$ to deactivate the polymerase reaction. Each dilution of $P$. infestans DNA was amplified twice.

ddPCR. A ddPCR was compared with real-time LAMP, PCR, and SYBR Green LAMP to detect $P$. infestans in infected potato tubers. ddPCR is a very sensitive assay and can detect the presence of DNA at very low concentrations, down to 1 copy/ $\mu$ l (Koepfli et al. 2016; Pinheiro et al. 2012). The ddPCR reaction consisted of $11 \mu \mathrm{l}$ of $2 \times$ ddPCR supermix (Bio-Rad, Hercules, CA), $1 \mu$ l each of a forward and reverse $20-\mu \mathrm{M}$ primer for real-time detection of $P$. infestans and $1.1 \mu \mathrm{l}$ of the associated probe (Ristaino et al. 2013), $6.9 \mu \mathrm{l}$ of molecular biology grade water, and $1 \mu \mathrm{l}$ of DNA (1 to $10 \mathrm{ng} / \mu \mathrm{l})$ in a $22-\mu \mathrm{l}$ reaction volume. The reaction was emulsified in $70 \mu \mathrm{l}$ of droplet oil (Bio-Rad) using a QX200 Droplet Generator before amplification. Thermal cycling conditions included $10 \mathrm{~min}$ at $95^{\circ} \mathrm{C}$ to activate the supermix, followed by 40 cycles of denaturation at $94^{\circ} \mathrm{C}$ for $30 \mathrm{~s}$ and annealing/extension at $60^{\circ}$ for $1 \mathrm{~min}$, after which the supermix was deactivated with a hold at $98^{\circ}$ for $10 \mathrm{~min}$, and then a final hold at $4^{\circ}$ C. Samples were analyzed on a QX200 Droplet Reader (Bio$\mathrm{Rad})$. The ddPCR experiment was repeated twice. The threshold for the detection of positive droplets was set at a fluorescence amplitude of 3,000 based on droplet patterns of positive and negative control samples (Fig. 3). Each experiment was repeated twice and final results for each sample were calculated based on an average of the two runs.

A LAMP mobile reader. A mobile LAMP reader was developed that consists of a tablet computer, a fiber optic cable, and a threedimensional printed sample reader designed to hold either $0.5-\mathrm{ml}$ sample tubes or lateral flow devices (Fig. 4). The reader uses the camera on the tablet to read and record fluorescence of each sample. Data readings from the camera are then sent to a cloud database. The reader was calibrated to read fluorescence of positive samples dyed 
with SYBR Green indicator dye, and data were recorded as an average pixel value (APV) in the software application on the tablet. Known positive and negative samples and a range of SYBR Green concentrations were used to calibrate the reader before measuring test samples to establish positive and negative thresholds. The reader was tested using known negative and positive samples and a set of LAMP reactions from 10 -fold serial dilutions $(10 \mathrm{ng} / \mu \mathrm{l}$ to $100 \mathrm{fg} / \mu \mathrm{l})$ of $P$. infestans DNA. The reader can also be used to detect the presence of a positive $P$. infestans sample on an LFD after LAMP with labeled primers by measuring for the presence/absence of the color strip in the test area (Cooper et al. 2012).

\section{Results}

LAMP visualization. The LAMP assay produced positive reactions only in $P$. infestans-infected potato or pure cultures using multiple methods of visualization. Positive LAMP results were read on a standard gel and were visualized as a ladder of fragments, whereas negative samples from healthy or non- $P$. infestans-infected tubers showed no signs of LAMP amplification (Fig. 1A). When SYBR Green was added to the LAMP reaction after amplification, positive samples changed color from orange to green, whereas negative samples remained orange (Fig. 1B). Positive samples visualized using HNB turned from violet to sky blue, whereas negative samples remained violet (Fig. 1C). The LAMP products were also visualized on an LFD after running the LAMP assay with DIG- and biotinlabeled LoopF and LoopB primers, respectively, following the LFD manufacturer's directions (Fig. 1D). A positive reaction on the LFD was indicated by a second band. All of the P. infestansinfected samples tested positive and healthy leaves were negative.

LAMP primer specificity and sensitivity. No positive reactions were detected when the $P$. infestans-specific LAMP primers were tested against a range of different species of bacteria, fungi, and other
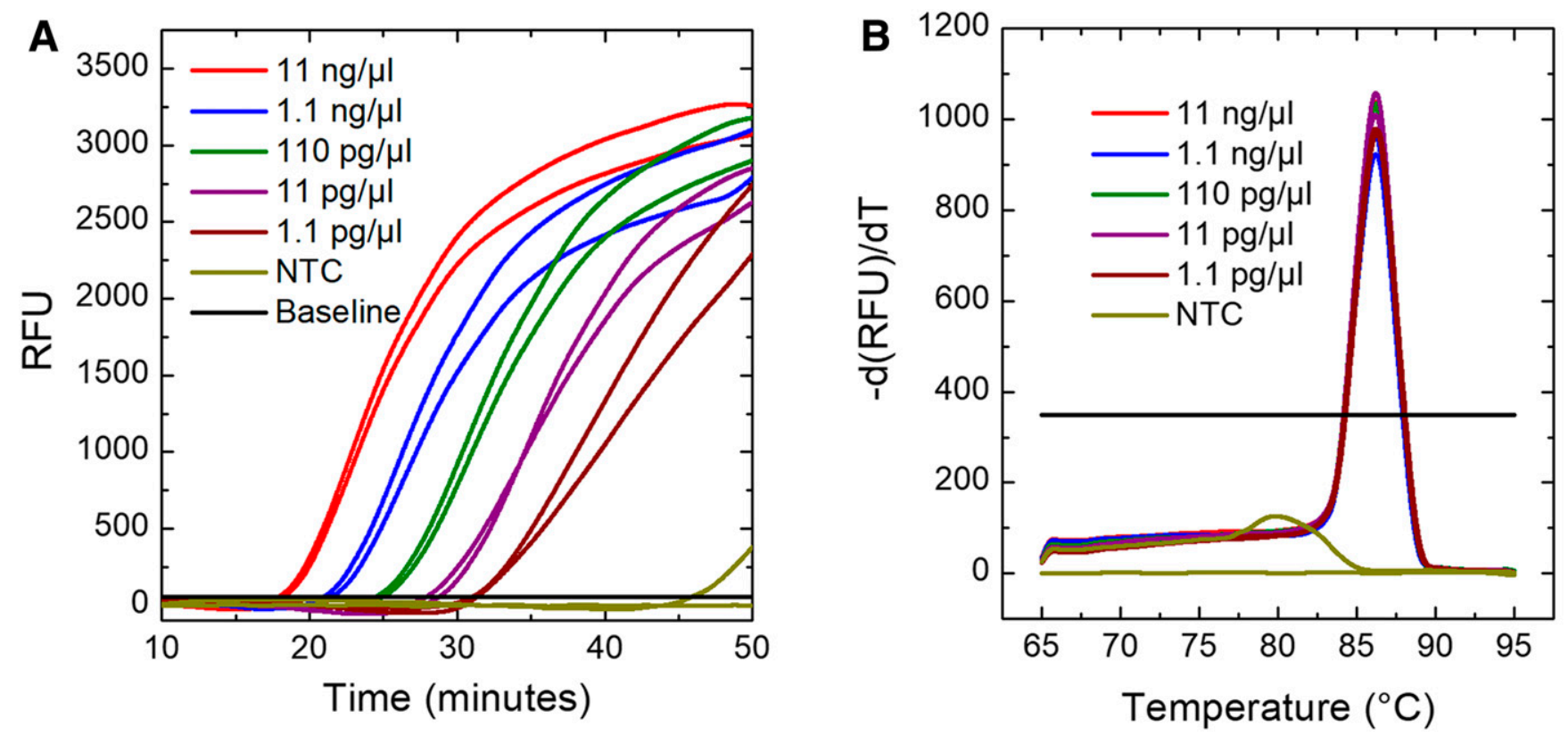

C

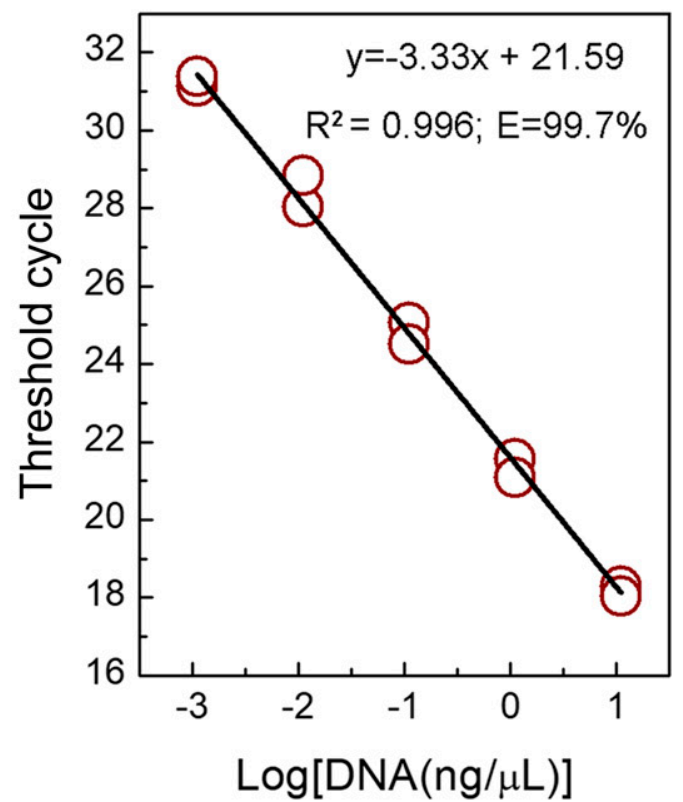

D

$11 \mathrm{ng} / \mu \mathrm{l}$

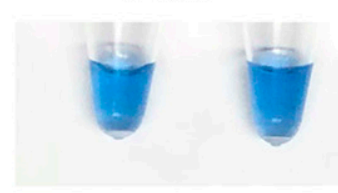

$101 \mathrm{pg} / \mu \mathrm{l}$

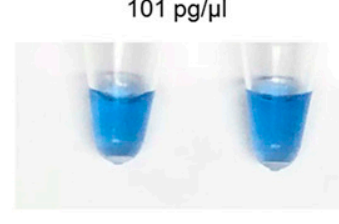

$1.1 \mathrm{pg} / \mu \mathrm{l}$

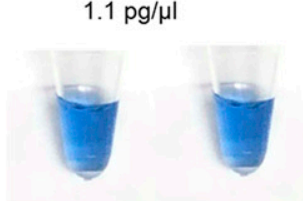

$1.1 \mathrm{ng} / \mu \mathrm{l}$

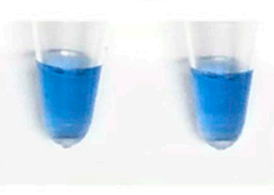

$11 \mathrm{pg} / \mu \mathrm{l}$

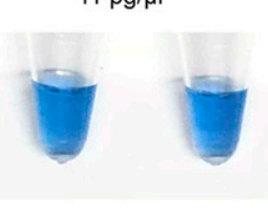

NTC
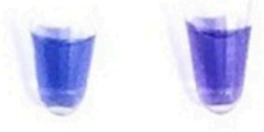

Fig. 2. Simultaneous fluorometric and colorimetric loop-mediated isothermal amplification (LAMP) assays for Phytophthora infestans using hydroxynaphthol blue (HNB) and EvaGreen dye. A, Real-time amplification curves of $P$. infestans DNA at different concentrations. RFU = relative fluorescence unit. B, Melt curve analysis of the amplicons, showing identical products. C, Standard curve for the real-time $P$. infestans LAMP assay. D, Colorimetric detection of LAMP amplification from the color change of HNB dye. 
Phytophthora species known to be pathogenic on tomato and/or potato and none of the 10 species of Phytophthora known to cause disease on tomato and/or potato reacted with the LAMP primers (Supplementary Table S1). In addition, the LAMP primers amplified all lineages of $P$. infestans tested from both the United States, European Union, and East Africa.

The LAMP primers were tested with a set of serial dilutions with DNA quantities ranging from $10 \mathrm{ng} / \mu \mathrm{l}$ to $100 \mathrm{fg} / \mu \mathrm{l}$. Positive reactions were reliably detected at DNA levels of $1 \mathrm{pg} / \mu \mathrm{l}$ (Table 1). The detection threshold of $P$. infestans by conventional PCR from our previous work was $10 \mathrm{pg} / \mu \mathrm{l}$ (Trout et al. 1997), so LAMP reactions were 10-fold more sensitive than PCR (Wangsomboondee and Ristaino 2002) (Table 1).

The LAMP primers were also tested on inoculated and healthy potato tubers from samples taken 7 days after inoculation. In two sets of experiments, the primers amplified $P$. infestans in all of the infected samples and none of the healthy tubers (100\% detection) (Table 2). The conventional PCR also amplified $P$. infestans in all of the inoculated and none of the healthy tubers; however, the LAMP assay was 10-fold more sensitive (Table 1).

Comparison with real-time LAMP and ddPCR. The same set of DNA was also tested using real-time LAMP and ddPCR. We monitored the LAMP reaction in real time using a serial dilution of DNA from $P$. infestans and also determined the optimum assay time. This HNB-enhanced real-time assay successfully amplified DNA at levels as low as $1.1 \mathrm{pg} / \mu \mathrm{l}$ (Fig. 2A) target DNA in an approximately 32-min reaction. After LAMP amplification, the melt curve analysis (Fig. 2B) showed a single melt peak of the amplification products $\left(\mathrm{T}_{\mathrm{m}}=\right.$ approximately $86^{\circ} \mathrm{C}$ ), confirming the presence of pure and identical amplicons in different samples. The standard curve illustrates the linear relationship between threshold cycle time and the logarithmic value of target DNA concentration (Fig. 2C). From the curve, the threshold cycle for the amplification of $1.1 \mathrm{pg} / \mu \mathrm{l}$ of $P$. infestans DNA was 31.4 and decreased on log scale with increasing initial DNA concentrations. After reaching the threshold value, the fluorescence signal increased exponentially in the following 8 to 10 cycles of amplification (Fig. 2A), and the HNB dye changed color from violet to sky blue for all positive samples (Fig. 2D). The no-template control began to give false-positive signals after $45 \mathrm{~min}$ of reaction (Fig. 2A), suggesting an optimal reaction time around $40 \mathrm{~min}$, which is long enough to amplify low DNA concentrations (approximately 1 $\mathrm{pg} / \mu \mathrm{l}$ ) before the appearance of any false-positive signals. Using real-time LAMP, the presence of $P$. infestans was detected in all of the inoculated tubers and in none of the healthy tubers that we tested. The average cycle threshold for inoculated tubers ranged from 24.99 to 32.53 cycles and was $>42$ cycles for healthy tubers (Table 2 ).

$P$. infestans was not detected in healthy tubers by ddPCR (Fig. $3 \mathrm{~A})$ and was detected in all of the inoculated tubers using ddPCR (Table 2). ddPCR can detect the presence of DNA at low copy numbers of molecules per microliter. Each point represents a reading from a single droplet and the infected tubers were clearly above
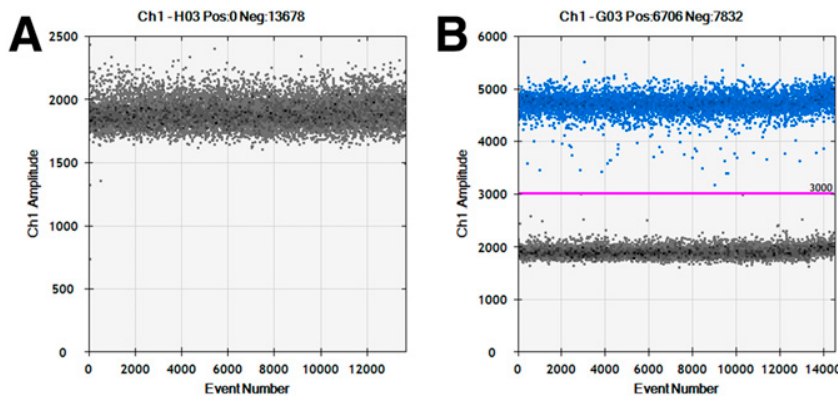

Fig. 3. Droplet digital PCR (ddPCR) for detection of Phytophthora infestans from $\mathbf{A}$, healthy and $\mathbf{B}$, infected potato tubers. Each point represents a reading from a single droplet indicating positive (above threshold line) or negative (below threshold line) reaction. The threshold for the detection of positive results was set at an amplitude of 3000 . the amplitude threshold of 3,000 (Fig. 3B). The average number of copies per microliter across two independent trials ranged from 0 to 0.145 copies/ $\mu$ l in healthy tubers and from 10.15 to 174.5 copies/ $\mu 1$ in infected tubers (Table 2). The lowest level of DNA detection by ddPCR was $100 \mathrm{fg} / \mu \mathrm{l}$, which was 100 -fold more sensitive than conventional PCR and 10-fold more sensitive than LAMP (Table 1).

LAMP mobile reader. The mobile LAMP reader (mReader; Mobile Assay, Boulder, CO; https://mobileassay.com/) consisted of a three-dimensional printed chamber that was attached to a tablet computer (Fig. 4A). The sample reader is attached to the tablet with a fiber optic cable and holds either a $0.5-\mathrm{ml}$ sample tube (Fig. 4B) or an LFD (Fig. 4D). The sample containers are covered with a flap to block out ambient light (Fig. 4B) The sample tube is placed in the reader and centered by aligning the tube with the camera image displayed on the tablet (Fig. 4C). A picture is taken with the tablet camera and uploaded to a cloud-based spreadsheet.

The mobile reader distinguished between $P$. infestans-infected potato tubers and leaf lesions and negative controls when visualized using SYBR Green LAMP. In the 10-fold serial dilutions (10 $\mathrm{ng} / \mu \mathrm{l}$ to $100 \mathrm{fg} / \mu \mathrm{l})$, differences in the APVs for $P$. infestans DNA were observed down to below $1 \mathrm{pg} / \mu \mathrm{l}$. The addition of a green filter over the camera lens enhanced the SYBR Green fluorescence reading. The average pixel values decreased with decreasing concentrations of DNA. Positive samples produce a high APV, whereas negative samples produce a very low APV. The average pixel value signal expression from the tablet reader was normalized from 0 to 1 and plotted on a 10 -fold log scale by fitting a Hill equation (Fig. 4E). The base, maximum, rate, and xhalf ( \pm 1 standard deviation) were $-1.3039 \pm 0.0877,1.0011 \pm 0.48,0.75836 \pm 0.153$, and $5.8468 \mathrm{e}-$ $05 \pm 1.64 \mathrm{e}+03$, respectively (Fig. $4 \mathrm{E}$ ). The half-maximum value from the Hill curve was $584 \mathrm{fg} / \mu \mathrm{l}$, indicating that the mReader was more sensitive at visualizing a positive sample of DNA than visualization by eye with SYBR Green or real-time LAMP with HNB.

\section{Discussion}

We developed highly specific LAMP primers for $P$. infestans that were able to detect the pathogen and not other Phytophthora species or fungal or bacterial species on potato. We evaluated the sensitivity of the LAMP assay using several methods. The SYBR Green and real-time LAMP assays were specific for $P$. infestans in potato and tomato and were 10-fold more sensitive than conventional PCR. In addition, we compared the sensitivity of the LAMP assays to ddPCR, a highly sensitive method for absolute quantification of DNA. The ddPCR was 100 -fold more sensitive $(100 \mathrm{fg} / \mu \mathrm{l})$ than either LAMP assay $(1 \mathrm{fg} / \mu \mathrm{l})$. The LAMP assay was effective in the detection of DNA extracted from pure cultures, from infected and dried plant leaf tissue, from infected tubers, and from DNA stored on FTA cards. Integration of SYBR Green LAMP with an mReader tablet improved the sensitivity of detection.

Through the modification of the primers and the use of visual dyes, LAMP primers can be adapted to strictly visual evaluation or to visualization on an LFD system. Each method has its own advantages and disadvantages, which should be taken into account when considering which method to use in a given scenario. SYBR Green provides a stark color change but requires the addition of SYBR Green to the sample tube after the reaction, which adds a step and could potentially introduce postreaction contamination. HNB can be added with the master mix and also provides a color change, but the transition from violet to blue can be hard to discern under bright light in the field, and the color change can be sensitive to changes in the $\mathrm{pH}$ of reagents. LFDs are easy to use and show a clear positive/negative reaction with a band on the LFD and are not dependent on interpreting color changes. However, LFDs also require postamplification mixing of the sample with a buffer and are more expensive than other visualization methods. In addition, the requirement for special single-use reading devices and modified primers can increase the cost of use.

Both the SYBR Green and LFD LAMP assays can be interpreted on the mobile mReader detection device. Modification of the mobile tablet with a three-dimensional printed tube holder or LFD case 
makes imaging results with the tablet camera easier and also allows data to be uploaded to the cloud and tracked. The mReader camera was more sensitive $(584 \mathrm{fg} / \mu \mathrm{l})$ than the human eye $(1 \mathrm{pg} / \mu \mathrm{l})$ in detecting true positives with SYBR Green than visual examination of a color change.

Currently, we have used the LAMP assay primarily in a laboratory setting but the protocol could be modified for field use. Methods such as the lyophilization of reagents or preservation using

A

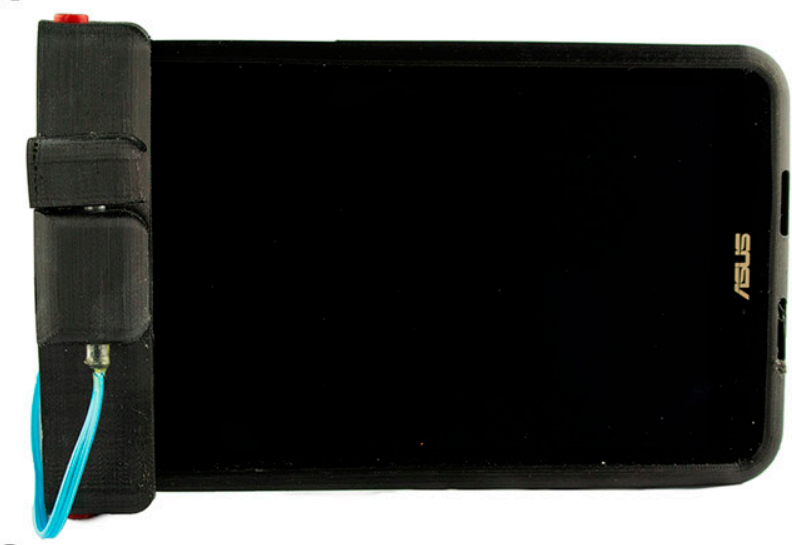

C

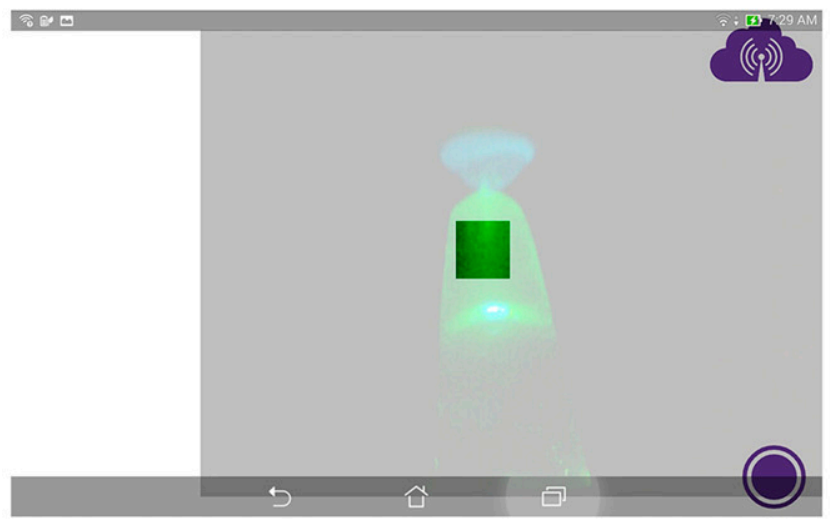

cryoprotectants may prove useful for increasing both ease of use and the shelf-life of the reagents outside of a laboratory (Chander et al. 2014; Chen and Ching 2017; Chen et al. 2016; Hayashida et al. 2015). Methods of preservation such as the addition of preservatives to ready prepared mixes of reagents and primers increase shelf stability and may also help with field readiness (Hamburger et al. 2013). Further experiments are underway to lyophilize and prepare fieldready reagents for LAMP.
B

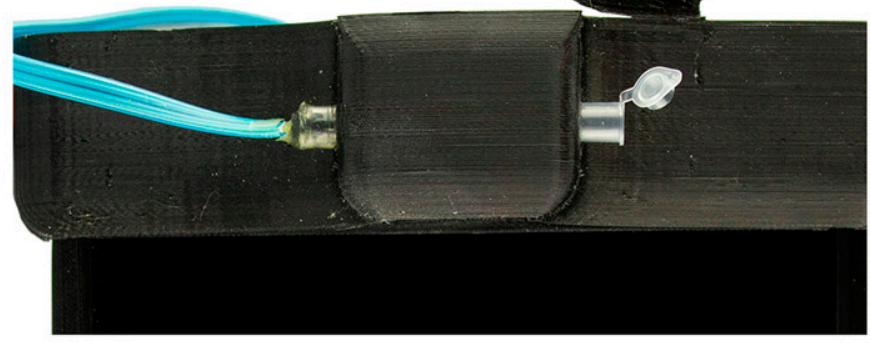

D

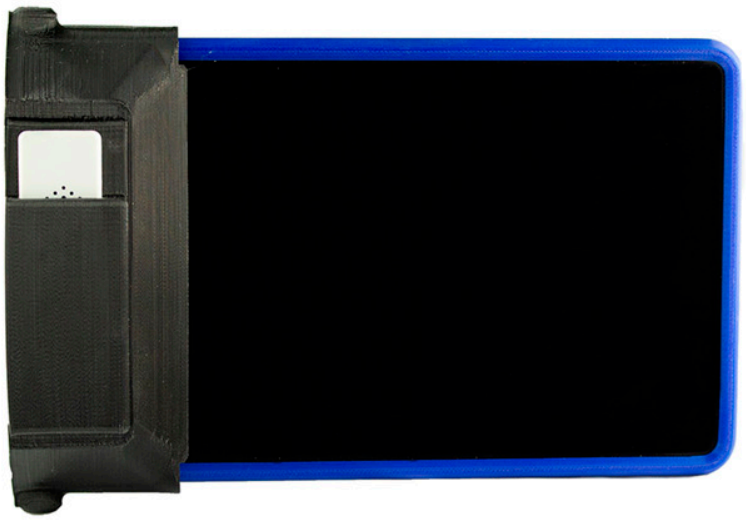

$\mathbf{E}$

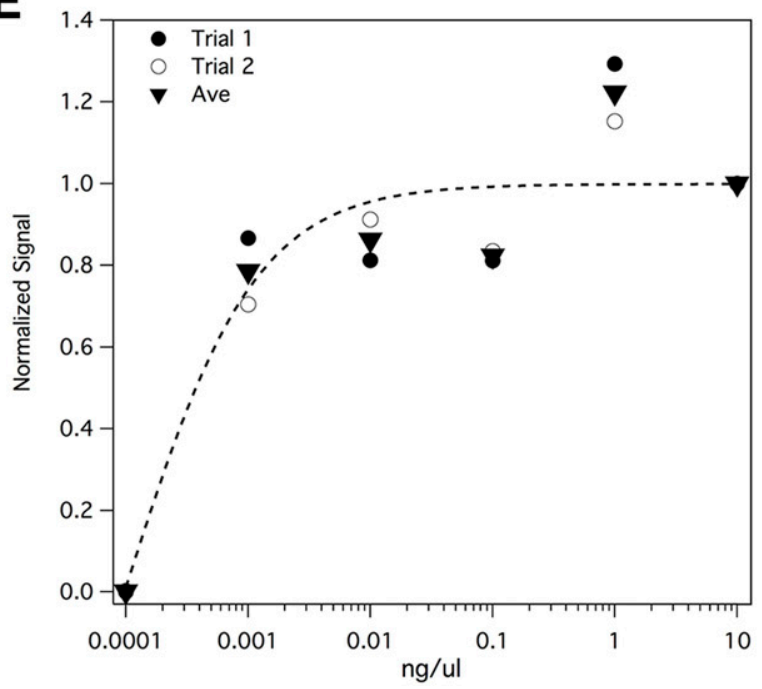

Fig. 4. Mobile reader (mReader) tablet for the detection of Phytophthora infestans in SYBR Green or lateral flow device loop-mediated isothermal amplification assays. A, Prototype of a 0.5 -ml tube reader. B, Entry port for loading sample tubes. A cover flap is used to block out ambient light while taking readings. C, Data collection app with a $P$. infestans-infected positive sample (fluorescence present) aligned in mReader. D, mReader with case modified for lateral flow devices. E, Signal expression from the tablet reader over the normalized range from 0 to 1 done by fitting a Hill equation. The half-maximum value is $584 \mathrm{fg} / \mu$ for lowest detection threshold. Parts A, B, and D courtesy of Joseph A. Ristaino; part B courtesy of A. Saville. 
To reduce false positives, we developed techniques to reduce or eliminate them. During the development of an assay for the detection of genetically modified organisms, Lee et al. (2009) suggested that repeated freeze-thaw cycles of the primers may result in the development of "primer intermediates" that may be amplified. We found that keeping all reagents and samples on ice when not in active use, including thawing reagents on ice instead of at room temperature, helped reduce false-positive occurrences. Reducing the amount of time dedicated to reaction set-up and setting up experiments in small batches of eight reactions was also useful. Adding primers to the master mix as a final step before adding DNA also reduced the chance of primer dimerization.

We also found that running the LAMP reaction for $<45$ min was important, as indicator dyes gave more false positives with longer

Table 1. Detection thresholds for dilutions of Phytophthora infestans DNA using conventional PCR, SYBR Green loop-mediated isothermal amplification (LAMP), real-time LAMP, and droplet digital PCR (ddPCR) ${ }^{\mathrm{a}}$

\begin{tabular}{lcccc}
\hline Concentration & PCR & LAMP & Real-time LAMP & ddPCR $^{\mathbf{c}}$ \\
\hline $10 \mathrm{ng} / \mu \mathrm{l}$ & + & + & + & + \\
$1 \mathrm{ng} / \mu \mathrm{l}$ & + & + & + & + \\
$100 \mathrm{pg} / \mu \mathrm{l}$ & + & + & + & + \\
$10 \mathrm{pg} / \mu \mathrm{l}$ & + & + & + & + \\
$1 \mathrm{pg} / \mu \mathrm{l}$ & - & + & + & + \\
$100 \mathrm{fg} / \mu \mathrm{l}$ & - & - & - & + \\
\hline
\end{tabular}

a Plus sign equals positive reaction for $P$. infestans DNA and minus sign equals negative reaction for $P$. infestans DNA. Conventional PCR used methods from Trout et al. (1997). Gel electrophoresis was used for PCR amplicon visualization and SYBR Green was used for LAMP amplicon visualization

${ }^{b}$ Real-time LAMP run on the CFX Connect Real-Time System (Bio-Rad).

${ }^{c}$ ddPCR was run on a Droplet Reader (Bio-Rad). assay run times $(1 \mathrm{~h})$. Optimization of the assay using real-time LAMP indicated that there is a threshold to the reaction time at which the potential for false positives increases. By reducing the reaction time to $<45 \mathrm{~min}$, we were able to eliminate the occurrence of falsepositive signals. The real-time LAMP used the combination of HNB with an intercalating dye (EvaGreen) to increase the effectiveness of the reaction. HNB interacts favorably with intercalating dyes, increasing their temperature stability and decreasing interference with the amplification process and therefore allowing for both greater changes in the fluorescent assay signal and fewer false-positive reactions (Kong et al. 2017). In addition, the combination of HNB and intercalating dyes such as EvaGreen allows for dual assay signal readout in both fluorometric and colorimetric modes, allowing for verification using both an electronic reader and the naked eye.

Careful development of primers for LAMP assays is important. With up to six primers interacting in a reaction, the number of opportunities for secondary structures to form is much higher and should be taken into consideration in the initial phases of primer development. Programs designed to develop LAMP primers from a given sequence (e.g., PrimerExplorer) help ensure that primer candidates meet the criteria for a successful LAMP assay. Potential primer sets should also be scrutinized both individually and collectively for properties that may result in the formation of primer dimers, such as a low value of the change in Gibbs free energy $(\Delta \mathrm{G})$.

The mobile tablet reader combined with real-time reporting of LAMP results has the potential to greatly reduce the amount of time needed to report a disease outbreak and alert stakeholders to disease outbreaks in their area, including in more remote areas. Using this type of system, it would be possible for a grower, crop consultant, or extension researcher to conduct a detection reaction at or near the point of collection of the pathogen and then quickly upload results to a cloud database. These data could then be projected onto an online tracking map. With the prevalence of inexpensive mobile

Table 2. Summary of detection results for Phytophthora infestans in healthy and infected potato tubers using conventional PCR, SYBR Green loop-mediated isothermal amplification (LAMP), real-time LAMP, and droplet digital PCR (ddPCR)

\begin{tabular}{|c|c|c|c|c|}
\hline Sample & $\mathbf{P C R}^{\mathbf{a}}$ & LAMPa & Real-time LAMP (mean Ct) ${ }^{b}$ & $\operatorname{ddPCR}(\text { copies/ } \mu \mathrm{l})^{\mathrm{c}}$ \\
\hline Healthy 1 & - & - & $>42$ & 0 \\
\hline Healthy 2 & - & - & $>42$ & 0.04 \\
\hline Healthy 3 & - & - & $>42$ & 0 \\
\hline Healthy 4 & - & - & $>42$ & 0.09 \\
\hline Healthy 5 & - & - & $>42$ & 0.135 \\
\hline Healthy 6 & - & - & $>42$ & 0.04 \\
\hline Healthy 7 & - & - & $>42$ & 0.145 \\
\hline Healthy 8 & - & - & $>42$ & 0.24 \\
\hline Healthy 9 & - & - & $>42$ & 0.15 \\
\hline Healthy 10 & - & - & $>42$ & 0 \\
\hline Healthy 11 & - & - & $>42$ & 0 \\
\hline Infected 1 & + & + & 25.8 & 48.85 \\
\hline Infected 2 & + & + & 31.8 & 10.15 \\
\hline Infected 3 & + & + & 32.53 & 20.45 \\
\hline Infected 4 & + & + & 30.06 & 18.7 \\
\hline Infected 14 & + & + & 27.21 & 23.35 \\
\hline Infected 15 & + & + & 30.16 & 18.55 \\
\hline Infected 18 & + & + & 24.99 & 83.05 \\
\hline Infected 20 & + & + & 25.1 & 174.5 \\
\hline Infected 22 & + & + & 26.79 & 36.2 \\
\hline Infected 24 & + & + & 25.09 & 63.5 \\
\hline Infected 25 & + & + & 27.27 & 6.25 \\
\hline Positive control & + & + & 25.8 & 916 \\
\hline Negative control & - & - & $>42$ & 0 \\
\hline Infected samples (range) & & & $24.99-32.3$ & $6.25-174.5$ \\
\hline Detection threshold & $10 \mathrm{pg} / \mu \mathrm{l}$ & $1 \mathrm{pg} / \mu \mathrm{l}$ & $1 \mathrm{pg} / \mu \mathrm{l}$ & $100 \mathrm{fg} / \mu \mathrm{l}$ \\
\hline
\end{tabular}

a Conventional PCR using methods from Trout et al. (1997). Gel electrophoresis was used for PCR amplicon visualization and SYBR Green was used for LAMP amplicon visualization. Plus sign equals positive reaction for $P$. infestans DNA and minus sign equals negative reaction for $P$. infestans DNA.

$\mathrm{b}$ The standard curve for real-time LAMP was $y=-3.33 x+21.59$, where $y=$ cycle threshold $(\mathrm{Ct})$ and $x=\log$ [DNA (in nanograms per microliter)]. Real-time LAMP was run on the CFX Connect Real-Time System (Bio-Rad).

c The threshold of detection was set at an amplitude of 3,000. The number of copies per microliter was determined from the average of readings from two separate trials. ddPCR was run on the Droplet Reader (Bio-Rad). 
devices, generating mobile readers for the detection of $P$. infestans and other pathogens is no longer a costly obstacle. A portable heat block for LAMP amplification could be added to the mReader for LAMP amplification in the field. The cost of the mReader with a heat block is approximately $\$ 450$ compared with much more expensive devices sold by other companies and could have application in places like Africa where cost, power sources, and internet connectivity may be an issue. Experiments are now underway in our laboratory to develop even more cost-effective, miniature devices to perform LAMP in the field using nanotechnology.

The mReader could be used in the development of new late blight detection networks for the developing world impacted by $P$. infestans in regions such as Latin America, Asia, or East Africa, where surveillance systems are not yet fully in place. The mobile reader is also being used to detect aflatoxins in corn, human, and foodborne pathogens.

We plan to beta test connecting data collected from mobile digital sensor platforms to the USABlight late blight tracking system (https://usablight.org) in the future. Currently, laboratory tests (e.g., microsatellite genotyping) are still needed to confirm specific genotypes but rapid confirmation of the presence of the pathogen itself would be valuable information and useful to either trigger a fungicide spray or not or to accept or reject a seed potato source. Our team has developed several novel pathogen detection applications that use microneedle patch DNA extractions or volatile organic compound sensors to detect $P$. infestans (Li et al. 2019; Paul et al. 2019).

The incorporation of sensitive detection assays with digital technologies into disease surveillance and pathogen detection surveys will allow growers to become citizen scientists and use new technologies to track plant disease outbreaks. Data collected from mobile applications can be used to create maps of pests or diseases in real time. The LAMP assays described here combined with a field-based mReader will improve data-driven decision making for growers.

\section{Acknowledgments}

The authors thank undergraduate student interns Sam Lee and Chris Lagaly for technical assistance and Anna Humphrey for assisting in assay validation. They also express appreciation to the many researchers who provided cultures of pathogens used in this study.

\section{Literature Cited}

Anderson, P. K., Cunningham, A. A., Patel, N. G., Morales, F. J., Epstein, P. R., and Daszak, P. 2004. Emerging infectious diseases of plants: Pathogen pollution, climate change and agrotechnology drivers. Trends Ecol. Evol. 19: 535-544.

Bourke, P. M. A. 1964. Emergence of potato blight, 1843-46. Nature 203:805-808. Chander, Y., Koelbl, J., Puckett, J., Moser, M. J., Klingele, A. J., Liles, M. R., Carrias, A., Mead, D. A., and Schoenfeld, T. W. 2014. A novel thermostable polymerase for RNA and DNA loop-mediated isothermal amplification (LAMP). Front. Microbiol. 5:395.

Chen, H. W., and Ching, W. M. 2017. Evaluation of the stability of lyophilized loop-mediated isothermal amplification reagents for the detection of Coxiella burnetii. Heliyon 3:e00415.

Chen, H. W., Weissenberger, G., and Ching, W. M. 2016. Development of lyophilized loop-mediated isothermal amplification reagents for the detection of Leptospira. Mil. Med. 181(suppl):227-231.

Chen, Q., Li, B., Liu, P., Lan, C., Zhan, Z., and Weng, Q. 2013. Development and evaluation of specific PCR and LAMP assays for the rapid detection of Phytophthora melonis. Eur. J. Plant Pathol. 137:597-607.

Cooke, L. R., Schepers, H. T. A. M., Hermansen, A., Bain, R. A., Bradshaw, N. J., Ritchie, F., Shaw, D. S., Evenhuis, A., Kessel, G. J. T., Wander, J. G. N., Andersson, B., Hansen, J. G., Hannukkala, A., Nærstad, R., and Nielsen, B. J. 2011. Epidemiology and integrated control of potato late blight in Europe. Potato Res. 54:183-222.

Cooper, D. C., Callahan, B., Callahan, P., and Burnett, L. 2012. Mobile image ratiometry: A new method for instantaneous analysis of rapid test strips. Nat. Preced. 10:1-2.

Cruz, C. V., Ardales, E., Skinner, D., Talag, J., Nelson, R., Louws, F., Leung, H., Mew, T., and Leach, J. 1996. Measurement of haplotypic variation in Xanthomonas oryzae pv. oryzae within a single field by rep-PCR and RFLP analyses. Studies 15:18.

Dai, T. T., Lu, C. C., Lu, J., Dong, S., Ye, W., Wang, Y., and Zheng, X. 2012. Development of a loop-mediated isothermal amplification assay for detection of Phytophthora sojae. FEMS Microbiol. Lett. 334:27-34.
Duan, Y., Ge, C., Zhang, X., Wang, J., and Zhou, M. 2014. A rapid detection method for the plant pathogen Sclerotinia sclerotiorum based on loopmediated isothermal amplification (LAMP). Australas. Plant Pathol. 43:61-66.

Fry, W. 2008. Phytophthora infestans: The plant (and R gene) destroyer. Mol. Plant Pathol. 9:385-402.

Fry, W. E., Birch, P. R. J., Judelson, H. S., Grünwald, N. J., Danies, G., Everts, K. L., Gevens, A. J., Gugino, B. K., Johnson, D. A., Johnson, S. B., McGrath, M. T., Myers, K. L., Ristaino, J. B., Roberts, P. D., Secor, G., and Smart, C. D. 2015. Five reasons to consider Phytophthora infestans a reemerging pathogen. Phytopathology 105:966-981.

Fukuta, S., Takahashi, R., Kuroyanagi, S., Miyake, N., Nagai, H., Suzuki, H., Hashizume, F., Tsuji, T., Taguchi, H., Watanabe, H., and Kageyama, K. 2013. Detection of Pythium aphanidermatum in tomato using loop-mediated isothermal amplification (LAMP) with species-specific primers. Eur. J. Plant Pathol. 136:689-701.

Gétaz, M., Bühlmann, A., Schneeberger, P. H. H., Van Malderghem, C., Duffy, B., Maes, M., Pothier, J. F., and Cottyn, B. 2017. A diagnostic tool for improved detection of Xanthomonas fragariae using a rapid and highly specific LAMP assay designed with comparative genomics. Plant Pathol. 66:1094-1102.

Goto, M., Honda, E., Ogura, A., Nomoto, A., and Hanaki, K. 2009. Colorimetric detection of loop-mediated isothermal amplification reaction by using hydroxy naphthol blue. Biotechniques 46:167-172.

Hall, T. A. 1999. BioEdit: A user-friendly biological sequence alignment editor and analysis program for Windows 95/08/NT. Nucleic Acids Symp. Ser. 41 95-98.

Hamburger, J., Abbasi, I., Kariuki, C., Wanjala, A., Mzungu, E., Mungai, P., Muchiri, E., and King, C. H. 2013. Evaluation of loop-mediated isothermal amplification suitable for molecular monitoring of schistosome-infected snails in field laboratories. Am. J. Trop. Med. Hyg. 88:344-351.

Hansen, Z. R., Knaus, B. J., Tabima, J. F., Press, C. M., Judelson, H. S., Grunwald, N. J., and Smart, C. D. 2016. Loop-mediated isothermal amplification for detection of the tomato and potato late blight pathogen, Phytophthora infestans. J. Appl. Microbiol. 120:1010-1020.

Hayashida, K., Kajino, K., Hachaambwa, L., Namangala, B., and Sugimoto, C. 2015. Direct blood dry LAMP: A rapid, stable, and easy diagnostic tool for human African trypanosomiasis. PLoS Negl. Trop. Dis. 9:e0003578.

Hu, C. H., Perez, F. G., Donahoo, R., McLeod, A., Myers, K., Ivors, K., Secor, G., Roberts, P. D., Deahl, K. L., Fry, W. E., and Ristaino, J. B. 2012. Recent genotypes of Phytophthora infestans in the eastern United States reveal clonal populations and reappearance of mefenoxam sensitivity. Plant Dis. 96: 1323-1330.

Khan, M., Li, B., Jiang, Y., Weng, Q., and Chen, Q. 2017. Evaluation of different PCR-based assays and LAMP method for rapid detection of Phytophthora infestans by targeting the Yptl gene. Front. Microbiol. 8:1920.

Koepfli, C., Nguitragool, W., Hofmann, N. E., Robinson, L. J., Ome-Kaius, M., Sattabongkot, J., Felger, I., and Mueller, I. 2016. Sensitive and accurate quantification of human malaria parasites using droplet digital PCR (ddPCR). Sci. Rep. 6:39183.

Kong, J. E., Wei, Q., Tseng, D., Zhang, J., Pan, E., Lewinski, M., Garner, O. B., Ozcan, A., and Di Carlo, D. 2017. Highly stable and sensitive nucleic acid amplification and cell-phone-based readout. ACS Nano 11:2934-2943.

Lee, D., La Mura, M., Allnutt, T. R., and Powell, W. 2009. Detection of genetically modified organisms (GMOs) using isothermal amplification of target DNA sequences. BMC Biotechnol. 9:7.

Lee, S. H., Baek, Y. H., Kim, Y.-H., Choi, Y.-K., Song, M.-S., and Ahn, J.-Y. 2016. One-pot reverse transcriptional loop-mediated isothermal amplification (RT-LAMP) for detecting MERS-CoV. Front. Microbiol. 7:2166.

Li, B., Liu, P., Xie, S., Yin, R., Weng, Q., and Chen, Q. 2015. Specific and sensitive detection of Phytophthora nicotianae by nested PCR and loopmediated isothermal amplification assays. J. Phytopathol. 163:185-193.

Li, Z., Paul, R., Ba Tis, T., Saville, A. C., Hansel, J. C., Yu, T., Ristaino, J. B., and Qingshan Wei, Q. 2019. Noninvasive plant disease diagnostics enabled by smartphone-based fingerprinting of leaf volatiles. Nat. Plants 5:856-866.

May, K. J., and Ristaino, J. B. 2004. Identity of the mtDNA haplotype(s) of Phytophthora infestans in historical specimens from the Irish potato famine. Mycol. Res. 108:471-479.

Mideros, M. F., Turissini, D. A., Guayazán, N., Ibarra-Avila, H., Danies, G., Cárdenas, M., Myers, K., Tabima, J., Goss, E. M., Bernal, A., Lagos, L. E., Grajales, A., Gonzalez, L. N., Cooke, D. E. L., Fry, W. E., Grünwald, N., Matute, D. R., and Restrepo, S. 2018. Phytophthora betacei, a new species within Phytophthora clade 1c causing late blight on Solanum betaceum in Colombia. Persoonia Mol. Phylog. Evol. Fungi 41:39-55.

Notomi, T., Okayama, H., Masubuchi, H., Yonekawa, T., Watanabe, K., Amino, N., and Hase, T. 2000. Loop-mediated isothermal amplification of DNA. Nucleic Acids Res. 28:e63.

Paul, R., Saville, A. C., Hansel, J. C., Ye, Y., Ball, C., Williams, A., Chang, X., Chen, G., Gu, Z., Ristaino, J. B., and Wei, Q. 2019. Extraction of plant DNA by microneedle patch for rapid detection of plant diseases. ACS Nano 13: 6540-6549.

Pinheiro, L. B., Coleman, V. A., Hindson, C. M., Herrmann, J., Hindson, B. J., Bhat, S., and Emslie, K. R. 2012. Evaluation of a droplet digital polymerase chain reaction format for DNA copy number quantification. Anal. Chem. 84: 1003-1011. 
Ravindran, A., Levy, J., Pierson, E., and Gross, D. C. 2012. Development of a loop-mediated isothermal amplification procedure as a sensitive and rapid method for detection of 'Candidatus Liberibacter solanacearum' in potatoes and psyllids. Phytopathology 102:899-907.

Ristaino, J., Cooke, D. E., Acuña, I., and Muñoz, M. 2019. The threat of late blight to global food security. Chapter 6 in: Emerging Plant Disease and Global Food Security. A. Records and J. Ristaino, eds. American Phytopathological Society, St. Paul, MN.

Ristaino, J. B. 2012. A Lucid key to the common species of Phytophthora. Plant Dis. 96:897-903.

Ristaino, J. B., Hu, C. H., and Fitt, B. D. L. 2013. Evidence for presence of the founder Ia mtDNA haplotype of Phytophthora infestans in 19th century potato tubers from the Rothamsted archives. Plant Pathol. 62:492-500.

Saville, A. C., Martin, M. D., and Ristaino, J. B. 2016. Historic late blight outbreaks caused by a widespread dominant lineage of Phytophthora infestans (Mont.) de Bary. PLoS One 11:e0168381.

Si Ammour, M., Bilodeau, G. J., Tremblay, D. M., Van der Heyden, H., Yaseen, T., Varvaro, L., and Carisse, O. 2017. Development of real-time isothermal amplification assays for on-site detection of Phytophthora infestans in potato leaves. Plant Dis. 101:1269-1277.

Thiessen, L. D., Keune, J. A., Neill, T. M., Turechek, W. W., Grove, G. G., and Mahaffee, W. F. 2016. Development of a grower-conducted inoculum detection assay for management of grape powdery mildew. Plant Pathol. 65:238-249.
Thompson, J. D., Higgins, D. G., and Gibson, T. J. 1994. Clustal-W: Improving the sensitivity of progressive multiple sequence alignment through sequence weighting, position-specific gap penalties and weight matrix choice. Nucleic Acids Res. 22:4673-4680.

Tomlinson, J. A., Barker, I., and Boonham, N. 2007. Faster, simpler, more-specific methods for improved molecular detection of Phytophthora ramorum in the field. Appl. Environ. Microbiol. 73:4040-4047.

Tomlinson, J. A., Dickinson, M. J., and Boonham, N. 2010. Rapid detection of Phytophthora ramorum and $P$. kernoviae by two-minute DNA extraction followed by isothermal amplification and amplicon detection by generic lateral flow device. Phytopathology 100:143-149.

Trout, C. L., Ristaino, J. B., Madritch, M., and Wangsomboondee, T. 1997. Rapid detection of Phytophthora infestans in late blight-infected potato and tomato using PCR. Plant Dis. 81:1042-1048.

Wang, H., Qi, M. Q., and Cutler, A. J. 1993. A simple method of preparing plant samples for PCR. Nucleic Acids Res. 21:4153-4154.

Wangsomboondee, T., and Ristaino, J. B. 2002. Optimization of sample size and DNA extraction methods to improve PCR detection of different propagules of Phytophthora infestans. Plant Dis. 86:247-253.

White, T. J., Bruns, T., Lee, S., and Taylor, J. 1990. Amplification and direct sequencing of fungal ribosomal RNA genes for phylogenetics. PCR Protoc. 18:315-322.

Yang, X., Tyler, B. M., and Hong, C. 2017. An expanded phylogeny for the genus Phytophthora. IMA Fungus 8:355-384. 